\title{
Socio-economic status determines risk of receptive syringe sharing behaviors among Iranian drug injectors; a national study
}

\author{
Shervin Assari ${ }^{1,2,3}$, Khodabakhsh Ahmadi ${ }^{4}$ and Majid Rezazade ${ }^{5}$ \\ ${ }^{1}$ Department of Psychiatry, School of Medicine, University of Michigan, Ann Arbor, MI, USA \\ ${ }^{2}$ Center for Research on Ethnicity, Culture, and Health (CRECH), School of Public Health, University of Michigan, Ann Arbor, MI, USA \\ ${ }^{3}$ Social Determinants of Health Research Center, University of Social Welfare and Rehabilitation, Tehran, Iran \\ ${ }^{4}$ Behavioral Sciences Research Center, Baqiyatallah University of Medical Sciences, Tehran, Iran \\ ${ }^{5}$ AIDS Prevention and Control Committee of Welfare Organization State, Tehran, Iran
}

Edited by:

Mohammadreza Mokhtari, Institute of Living, USA

\section{Reviewed by:}

Arezoo Shajiei, Mashhad University of Medical Sciences, Iran

Mohammadreza Mokhtari, Institute of Living, USA

Masoumeh Dejman, University of

Social Welfare and Rehabilitation

Sciences, Iran

\section{*Correspondence:}

Shervin Assari, Department of Psychiatry, School of Medicine, University of Michigan, 4250

Plymouth Road, Ann Arbor, MI 48109-2700, USA

e-mail: assari@umich.edu
Background: Although needle and syringe sharing is one of the main routs of transmission of HIV in several countries in the middle east, very little is known about how socio-economic status of injecting drug users (IDUs) is linked to the receptive syringe sharing behaviors in these countries.

Aim: To study socio-economic correlates of receptive needle and syringe sharing among IDUs in Iran.

Methods: The study used data from the Unhide Risk Study, a national survey of IDUs. This study sampled 636 IDUs (91\% male) via snowball sampling from eight provinces in Iran in 2009. Socio-demographic and drug use characteristics were collected. We used a logistic regression to determine factors associated with receptive needle and syringe sharing during the past 6 months.

Results: From 636 IDUs enrolled in this study, 68\% $(n=434)$ reported receptive needle and syringe sharing behaviors in the past 6 months. Odds of receptive needle and syringe sharing in the past 6 months was lower among IDUs who were male lodds ratios $(\mathrm{OR})=0.29$, 95\% confidence interval $(\mathrm{Cl})=0.12-0.70]$, had higher education $(\mathrm{OR}=0.74$, $95 \% \mathrm{Cl}=0.64-0.86)$ but higher among those who were unemployed $(\mathrm{OR}=4.05,95 \%$ $\mathrm{Cl}=1.50-10.94)$, and were single $(\mathrm{OR}=1.47,95 \% \mathrm{Cl}=1.02-2.11)$.

Conclusion: This study presented factors associated with risk of receptive needle and syringe sharing among Iranian IDUs. This information may be used for HIV prevention and harm reduction purposes. Socio-economic status of Iranian IDUs may be closely linked to high-risk injecting behaviors among them.

Keywords: injection drug users, HIV, needle and syringe sharing, socio-demographics, Iran

\section{INTRODUCTION}

Increasing trend of HIV and AIDS is a global health challenge (1). In several Middle Eastern countries, this epidemic is closely attached to the pattern of high-risk injecting behaviors among injecting drug users (IDUs) (2). In Iran, at least 6 of $10 \mathrm{HIV}$ positive cases and 8 of 10 AIDS cases occur among IDUs (3). In Iran, needle-sharing behaviors have been consistently shown to be a main route of HIV transmission (4-8).

The Iranian Ministry of Health has recently announced an estimated figure of 200,000 IDUs in Iran (9). Although Iran has a number of harm reduction programs for tackling epidemics of HIV and other blood born infections among IDUs and other highrisk groups $(6,10-12)$, prevalence of HIV is increasing rapidly among infections among IDUs in Iran (6). High prevalence of HIV (10-20\%) and HCV (30-50\%) among Iranian drug injectors is well known (13-18). High prevalence of HIV and other blood born infections among Iranian IDUs have been attributed to their high rate risk-behaviors such as shared injection and needle sharing $(3,6-8,19,20)$.

Globally, rate of syringe sharing varies based on geographic regions. Shared injecting behaviors have been reported to be from $25 \%$ in Canada (21) to $80 \%$ in Mexico (19). Prevalence of shared injection among Iranian IDUs differs widely from one study to another. Lifetime needle and syringe sharing among IDUs was one-third among IDUs in 2009 (19), half in one national survey in 1999 (20), and finally two-thirds in another study published in 2006 (5).

A wide range of socio-economic factors may be associated with high-risk injecting behaviors among IDUs. Socio-demographic characteristics such as gender (19), marital/partnership status (22), employment (19), economic status (19), living condition (19), and place of residence (23) may influence pattern of risk-behaviors 
among IDUs. In addition to the socio-economic factors, drug use characteristics such as years passed from first drug injection (24), frequency $(21)$ and setting $(25,26)$ of injection, and poly drug use (21) may influences high-risk injections of IDUs. HIV sero-status and HIV knowledge may also contribute to high-risk injections of IDUs (22).

In Iran, little is known about the socio-economic and drugrelated predictors of risk-behaviors among Iranian IDUs (3, 6, 7). A recent report suggested that female gender [odds ratios $(\mathrm{OR})=2.68$ ] and being jobless $(\mathrm{OR}=1.87)$ were associated with higher risk of shared injection, while being alone at most injections $(\mathrm{OR}=0.51)$ was associated with lower risk of needle and syringe sharing (19). That study is, however, limited for two reasons. First, the study entered other high-risk-behaviors to the list of predictors of lifetime needle sharing in the model. Including other risk factors may result in over adjustment or at least un-necessary adjustment (27-29). Secondly, as outcome is lifetime needle and syringe sharing history (19), we do not have information on receptive sharing behaviors.

To set harm reduction policies, policy makers need information on rate and associated factors of risky behavior. This study is thus aimed to determine the rate and predictors of receptive needle and syringe sharing among Iranian IDUs.

\section{MATERIALS AND METHODS DESIGN AND SETTING}

With a cross-sectional design, data came from Unhide Risk, a national survey of IDUs. This study sampled 636 IDUs (91\% male) via snow ball sampling from eight provinces in Iran in 2009. Some other manuscripts have been published from this database (30-32).

\section{CODES OF ETHICS}

The study was approved by the ethical review committee of the Baqiyatallah University of Medical Sciences. Informed consent was obtained from all the participants after they had been verbally reassured that the information would be kept confidential, especially from the correctional system. All questionnaires were anonymous. No financial incentives were given to the participants, however, all participants received HIV education, and also free syringes and condoms.

\section{PROCESS}

Data were collected via structured interviews, using a questionnaire. Interviews were performed by research area specialists who had received trainings through workshops held in Tehran, Iran. Each interview took up to $60 \mathrm{~min}$.

Data were collected using paper-based questionnaires, which included: (1) socio-demographic, (2) family data, (3) history of childhood trauma, (4) HIV attitude, (5) HIV knowledge, (6) Injection Behavior, (7) sexual behavior, and (8) HIV test.

\section{OUTCOME}

Receptive needle and syringe sharing during the past 6 months was measured using these two questions: (A) During the last month, how many times did you inject drugs using shared syringe/needle? Answers included (0) never, (1) only 1-3 times, (2) once a month, (3) 2-3 times a month, (4) 1 time per week, (5) 2-6 times a week,
(6) 1 time per day, (7) 2-3 times a day, and (8) 4 times or more a day. (B) During the past 6 months, provided that using shared syringes, usually how many people had injected by that used syringe, before your injection? Answer of 1 or more to both above questions were considered as receptive needle sharing. The 6-month interval has been used for assessing needle sharing, previously $(22,33)$.

\section{STATISTICAL ANALYSIS}

The data obtained in the Statistical Package for the Social Sciences 17 (SPSS Inc, IL, USA) for Windows. In addition to descriptive statistics that included mean and standard deviation (SD) and also median and first and third quartile (25th and 75th percentiles). For bivariate analysis, independent samples $t$-test, and chi-square tests were used. Multivariate stepwise logistic regression was used to determine the predictors of receptive syringe and needle sharing. ORs and $95 \%$ Confidence Interval (CI) were reported. $P$ value $<0.05$ was considered significant.

\section{RESULTS}

All 636 participants were street-based IDUs, $71.5 \%$ of whom were daily injectors $(n=455) .91 .1 \%$ were male, $57.8 \%$ were single, $59.3 \%$ were employed, and only $8.3 \%$ were illiterate.

Mean age of the IDUs was $31.5 \pm 7.8$ year. Details of baseline data are presented in Table 1.

\section{RECEPTIVE NEEDLE AND SYRINGE SHARING BEHAVIORS}

Two IDUs $(0.3 \%)$ did not answer our questions regarding the receptive sharing, and $68 \%$ of IDUs $(n=434)$ reported receptive needle and syringe sharing.

Using the Pearson Chi-square test for bivariate analysis showed that being female $(\mathrm{OR}=1.07,95 \% \mathrm{CI}=1.02-1.11)$, experience of abuse during childhood $(\mathrm{OR}=1.41,95 \% \mathrm{CI}=1.23-1.61)$, and unemployment $(\mathrm{OR}=1.05,95 \% \mathrm{CI}=1.01-1.08)$ were associated with higher likelihood of receptive needle and syringe sharing. There was not a significant association between received sharing and living alone or being illiterate ( $p>0.05$ for all) (Table 2).

Based on the independent samples $t$-test, mean age was not significantly different between those with (31.4 \pm 7.9 years $)$ and without ( $31.6 \pm 7.8$ years) received needle sharing $(p=0.75)$.

Logistic regression showed that the likelihood of receptive needle and syringe sharing in that past 6 months was positively associated with being jobless $(\mathrm{OR}=4.05,95 \% \mathrm{CI}=1.50-10.94)$, being single $(\mathrm{OR}=1.47,95 \% \mathrm{CI}=1.02-2.11)$, and negatively associated with male gender $(\mathrm{OR}=0.29,95 \% \mathrm{CI}=0.12-0.70)$, and having a higher educational level $(\mathrm{OR}=0.74,95 \% \mathrm{CI}=0.64-0.86)$ (Table 3).

\section{DISCUSSION}

According to the current study, in Iran, about two of three IDUs report receptive needle and syringe sharing. Receptive needle and syringe sharing seems to be higher among female, unemployed, single, and less educated IDUs.

The rate reported in this study seems alarming and higher than some previously reported rates $(19,20)$. Our report is very similar to the rate reported by Day et al. on the patterns of drug use among a sample of drug users and IDUs attending a general practice in Iran in 2006 (5). That report however was a single center, in clinical setting, reporting shared injection among IDUs $(n=292)$ who 
Table 1 | Socio-demographic and injection frequency among Iranian IDUs $(n=636)$

\begin{tabular}{|c|c|c|}
\hline Characteristics & $n$ & $\%$ \\
\hline \multicolumn{3}{|l|}{ Socio-demographic data } \\
\hline \multicolumn{3}{|l|}{ Gender } \\
\hline Male & 581 & 91.1 \\
\hline Female & 44 & 6.9 \\
\hline Missing & 13 & 2.0 \\
\hline \multicolumn{3}{|l|}{ Marital status } \\
\hline Single & 369 & 57.8 \\
\hline Married & 262 & 41.1 \\
\hline Missing & 7 & 1.1 \\
\hline \multicolumn{3}{|l|}{ Educational level } \\
\hline Illiterate & 53 & 8.3 \\
\hline Primary & 140 & 21.9 \\
\hline Guidance school & 232 & 36.4 \\
\hline High school & 95 & 14.9 \\
\hline High school diploma & 90 & 14.1 \\
\hline University degree & 21 & 3.5 \\
\hline Missing & 6 & 0.9 \\
\hline \multicolumn{3}{|l|}{ Living status } \\
\hline Alone & 102 & 16.0 \\
\hline With someone & 531 & 83.2 \\
\hline Missing & 5 & 0.8 \\
\hline \multicolumn{3}{|l|}{ Housing } \\
\hline Live in others house & 335 & 52.5 \\
\hline Live in own/rental house & 273 & 42.8 \\
\hline Missing & 30 & 4.7 \\
\hline \multicolumn{3}{|l|}{ Employment } \\
\hline Jobless & 234 & 36.7 \\
\hline Employed & 378 & 59.3 \\
\hline Missing & 26 & 4.1 \\
\hline \multicolumn{3}{|l|}{ Injection frequency } \\
\hline 2-3 times a month & 62 & 9.7 \\
\hline Once a week & 53 & 8.3 \\
\hline 2-6 times a week & 67 & 10.5 \\
\hline Once a day & 131 & 20.5 \\
\hline 2-3 times a day & 198 & 31.0 \\
\hline 4 times or more a day & 127 & 19.9 \\
\hline
\end{tabular}

were limited from a clinical setting in the capital of Iran. Our rate is, however, only receptive syringe sharing among a community sample of IDUs $(n=636)$ enrolled from eight provinces and has sampled setting.

There is scarce data on the rate, reasons, risk factors and consequences of needle, and syringe sharing among Iranian IDUs. Based on one study, half of the IDUs had shared injection paraphernalia 1-2 months prior to interview. Sharing in prisons was stated to be the rule. Reasons for sharing were indicated as difficulty of purchasing syringes in inaccessible hours, hesitance of pharmacists to sell syringes and also financial strains. The main reason for avoiding sharing among IDUs was the fear of acquiring HIV (34).

A qualitative study of IDUs in Iran reported a possible reduction in the needle sharing. That study however showed that IDUs
Table 2 | Comparison of socio-demographic and injection frequency among Iranian injection drug users with and without receptive syringe sharing $(n=636)$.

\begin{tabular}{|c|c|c|c|}
\hline & \multicolumn{2}{|c|}{$\begin{array}{l}\text { Receptive syringe } \\
\text { sharing }\end{array}$} & \multirow[t]{2}{*}{ Sig. $^{a}$} \\
\hline & Yes $N=434$ & No $N=202$ & \\
\hline Female & $38(9.0)$ & $6(3.0)$ & 0.006 \\
\hline Single & $261(61.0)$ & $108(53.7)$ & 0.085 \\
\hline Unemployed & $30(6.9)$ & $5(2.5)$ & 0.022 \\
\hline Lived alone & $74(17.1)$ & $28(13.9)$ & 0.308 \\
\hline Positive history of childhood abuse & $216(51.1)$ & $62(31.0)$ & $<0.001$ \\
\hline Daily injector & $319(73.5)$ & $136(67.3)$ & 0.108 \\
\hline Illiterate & $45(10.4)$ & $8(4.0)$ & 0.821 \\
\hline
\end{tabular}

${ }^{a}$ Chi-square test was employed.

Outcome was missed in two participants.

Table 3 | Summary of findings of binary logistic regression on socio-economic and drug-related factors associated with receptive syringe sharing among injection drug users $(n=636)$.

\begin{tabular}{lllr}
\hline Characteristics & Exp (B) & \multicolumn{2}{c}{$\begin{array}{l}\text { 95\% C.I. for } \\
\text { Exp (B) }\end{array}$} \\
\cline { 3 - 4 } & & Lower & Upper \\
\hline Gender (male) & & 0.12 & 0.70 \\
Marital status (single) & 0.29 & 1.02 & 2.11 \\
Higher educational level & 1.47 & 0.64 & 0.86 \\
Unemployment & 0.74 & 1.50 & 10.94 \\
\hline
\end{tabular}

Variable(s) entered on this model included age, gender, marital status, educational level, unemployment, living alone, injection frequency, and history of childhood abuse.

continue to share drugs in locations of group injection, and in states of withdrawal or severe addiction. That qualitative study stated being homeless, female, and young age as possible factors that may increase the risks for HIV among IDUs. System-wise barriers to harm reduction listed by participants included the cost or stigma of purchasing needles from pharmacies, over-burdened clinics, irregular enforcement of laws protecting IDU, and lack of efforts to address the sexual risks of IDU (8).

In a recent national study on more than 2,000 IDUs in Iran in 2007 , lifetime needle and syringe sharing was associated with female gender, being jobless, having illegal income, and history of drug use by family members (35). The first two risk factors reported by that study was also associated with a higher likelihood of receptive syringe sharing among our sample. The outcome, was, however, different in the two studies.

Our study showed a higher likelihood of receptive needle and syringe sharing among female IDUs. Gender has been reported as a factor associated with sharing behaviors in both Iran (35) and in other countries $(36,37)$. A qualitative study of Iranian female IDUs reported sharing syringes as a typical behavior of IDUs (6). As a result, needle exchange programs need to be sensitive to gender of the target IDU population (38). 
Based on the Theory of Gender and Power, the sexual division of labor, the sexual division of power, and the structure of cathexis are the main structures that influence distribution of risk based on gender in a society. Based on this theory, which was developed by Connell in 1987, major gender differences in employment, income, and education may contribute to power imbalances and subordination of women in many aspects in most societies. Due to such inequalities, women are more frequently exposed to risk factors that ultimately influence their well-being (39).

In our study, compared to those with a job, unemployed IDUs were at a higher risk of receptive needle and syringe sharing. Review of literature shows a link between unemployment of IDUs and needle and syringe sharing behavior $(40,41)$. This might be a direct result of financial strains of unemployment, or a more complex pathway, such as network or associated traits.

In Iran, evidences have shown that access to a needle and syringe program will reduce the needle and syringe sharing practices of the IDUs (8). A quantitative study with cross-sectional design reported that shared use of needle/syringe in the past month was significantly lower among IDUs who received estimated $\geq 7$ syringes per week than those who did not $(O R=14.36)$, and the findings suggest that the outreach program in Tehran has reduced direct sharing among those who received more than several needles/syringes from the program (42). Another quantitative study in 2005, on 419 street-based IDUs in Tehran compared self-reported needle and syringe access and use between IDUs from a neighborhood with an active NSP to IDUs from a neighborhood without such an intervention. A significantly smaller proportion of IDUs from the former neighborhood reported having used a shared needle/syringe over a 1-month period $(21.0 \%)$ compared to IDUs from the latter neighborhood $(39.9 \%)$ $(\mathrm{OR}=0.24)$. That study documented a success of the NSP programs in Iran in reducing needle and syringe sharing practices among IDUs (8).

There are some limitations to this study. First, cross-sectional design of the study limits any causal inference. Future research should go beyond cross-sectional studies and test direction of the associations reported in this study. We did not have data on social context and social network of the IDUs. We also did not enter access to needle exchange programs or HIV education programs to our study. The study relies on participants' self-report data, which may be affected by response bias. Thus we cannot rule out the possibility of underreported shared injection due to social desirability of the IDUs (43). As samples were not random, findings are not representative of all IDUs.

\section{CONCLUSION}

Intervention programs that target to reduce HIV risk through promotion of safe injection among Iranian IDUs should consider socio-economic characteristics of their target populations. Such programs may need to enhance enrolment of female, unemployed, single, and less educated IDUs who are at highest risk of receptive needle-sharing behaviors.

\section{ACKNOWLEDGMENTS}

The study was supported by the Global Fund to Fight AIDS, Tuberculosis and Malaria (GFATM), United Nations Development
Program (UNDP). The study was conducted under signed Memorandums of Understanding (MOU) between UNDP, Center for Disease Control (CDC) of Iranian Ministry of Health and Medical Education (MOHME), National Iranian Welfare Organization, Behavioral Sciences Research Center, Tehran, Iran, Medicine and Health Promotion Institute and Universal Network for Health Information Dissemination and Exchange (UNHIDE). All authors have substantial contributions to conception, design, and interpretation of data, and have approved the final version of the paper. Authors would like to thank Aurora Turek and Ashley Heilingoetter, University of Michigan, for input to the early version of this manuscript.

\section{REFERENCES}

1. Network MAP. AIDS in Asia: Face the Facts. A Comprehensive Analysis of the AIDS Epidemic in Asia. Washington, DC: Monitoring the AIDS Pandemic (MAP) Network (2004).

2. Reid SR. Injection drug use, unsafe medical injections, and HIV in Africa: a systematic review. Harm Reduct J (2009) 6:24. doi:10.1186/1477-7517-6-24

3. Razani N, Mohraz M, Kheirandish P, Malekinejad M, Malekafzali H, Mokri A, et al. HIV risk behavior among injection drug users in Tehran, Iran. Addiction (2007) 102(9):1472-82. doi:10.1111/j.1360-0443.2007.01914.x

4. Rahbar RA, Rooholamini S, Khoshnood K. Prevalence of HIV infection and other bloodborne infections in incarcerated and non-incarcerated injection drug users (IDUs) in Mashhad, Iran. Int J Drug Policy (2004) 15(2):151-5. doi:10.1016/j.drugpo.2003.07.001

5. Day C, Nassirimanesh B, Shakeshaft A, Dolan K. Patterns of drug use among a sample of drug users and injecting drug users attending a general practice in Iran. Harm Reduct J (2006) 3:2. doi:10.1186/1477-7517-3-2

6. Razzaghi EM, Movaghar AR, Green TC, Khoshnood K. Profiles of risk: a qualitative study of injecting drug users in Tehran, Iran. Harm Reduct J (2006) 3(12):12. doi:10.1186/1477-7517-3-12

7. Vazirian M, Nassirimanesh B, Zamani S, Ono-Kihara M, Kihara M, Ravari SM, et al. Needle and syringe sharing practices of injecting drug users participating in an outreach HIV prevention program in Tehran, Iran: a cross-sectional study. Harm Reduct J (2005) 7(2):19. doi:10.1186/1477-7517-2-19

8. Zamani S, Vazirian M, Nassirimanesh B, Razzaghi EM, Ono-Kihara M, Mortazavi Ravari S, et al. Needle and syringe sharing practices among injecting drug users in Tehran: a comparison of two neighborhoods, one with and one without a needle and syringe program. AIDS Behav (2010) 14(4):885-90. doi:10.1007/s10461-008-9404-2

9. Gheiratmand R, Navipour R, Mohebbi MR, Mallik AK. Uncertainty on the number of HIV/AIDS patients: our experience in Iran. Sex Transm Infect (2005) 81(3):279-80. doi:10.1136/sti.2004.012880

10. Shafer KP, Hahn JA, Lum PJ. Prevalence and correlates of HIV infection among young injection drug users in San Francisco. J AIDS (2002) 31:422-31.

11. Monga HK, Rodrguez-Barradas MC, Breaux K. Hepatitis C virus infectionrelated morbidity and mortality among patients with human immunodeficiency virus infection. Clin Infect Dis (2001) 33(240):247. doi:10.1086/321819

12. Falstar K, Kaldor JM, Maher L. Hepatitis C acquisition among injection drug users: a cohort analysis of a national repeated cross-sectional survey of needle and syringe program attendees in Australia 1995-2004. J Urban Health (2009) 86(1):106-18. doi:10.1007/s11524-008-9330-7

13. Zamani S, Radfar R, Nematollahi P, Fadaie R, Meshkati M, Mortazavi S, et al. Prevalence of $\mathrm{HIV} / \mathrm{HCV} / \mathrm{HBV}$ infections and drug-related risk behaviours amongst IDUs recruited through peer-driven sampling in Iran. Int J Drug Policy (2010) 21(6):493-500. doi:10.1016/j.drugpo.2010.04.006

14. Sofian M, Aghakhani A, Banifazl M, Azadmanesh K, Farazi AA, McFarland W, et al. Viral hepatitis and HIV infection among injection drug users in a central Iranian city. J Addict Med (2012) 6(4):292-6. doi:10.1097/ADM. 0b013e3182659928

15. Sharif M, Sherif A, Sayyah M. Frequency of HBV, HCV and HIV infections among hospitalized injecting drug users in Kashan. Indian J Sex Transm Dis (2009) 30(1):28-30. doi:10.4103/0253-7184.55477

16. Davarpanah MA, Khademolhosseini F, Rajaeefard A, Tavassoli A, Yazdanfar SK, Rezaianzadeh A. Hepatitis C virus infection in HIV positive attendees of Shiraz 
behavioral diseases consultation center in Southern Iran. Indian J Community Med (2013) 38(2):86-91. doi:10.4103/0970-0218.112437

17. Alipour A, Haghdoost AA, Sajadi L, Zolala F. HIV prevalence and related risk behaviours among female partners of male injecting drugs users in Iran: results of a bio-behavioural survey, 2010. Sex Transm Infect (2013) 89(Suppl 3):iii41-4. doi:10.1136/sextrans-2013-051201

18. Rahimi-Movaghar A, Razaghi EM, Sahimi-Izadian E, Amin-Esmaeili M. HIV, hepatitis $\mathrm{C}$ virus, and hepatitis $\mathrm{B}$ virus co-infections among injecting drug users in Tehran, Iran. Int J Infect Dis (2010) 14(1):e28-33. doi:10.1016/j.ijid. 2009.03.002

19. Rafiey H, Narenjiha H, Shirinbayan P, Noori R, Javadipour M, Roshanpajouh M, et al. Needle and syringe sharing among Iranian drug injectors. Harm Reduct $J$ (2009) 30(6):21. doi:10.1186/1477-7517-6-21

20. Razzaghi EM, Rahimi Movaghar A, Hosseini M, Madani S, Chatterjee A. Rapid Situation Assessment of Drug Abuse in Iran. Tehran: Iranian Welfare Organization (1999).

21. Wood E, Tyndall MW, Spittal PM, Li K, Kerr T, Hogg RS, et al. Unsafe injection practices in a cohort of injection drug users in Vancouver: could safer injecting rooms help? CMAJ (2001) 165(4):405-10.

22. Gu J, Wang R, Chen H, Lau JT, Zhang L, Hu X, et al. Prevalence of needle sharing, commercial sex behaviors and associated factors in Chinese male and female injecting drug user populations. AIDS Care (2009) 21(1):31-41. doi:10.1080/09540120802068787

23. Zerden Lde S, Marilis López L, Lundgren LM. Needle sharing among Puerto Rican injection drug users in Puerto Rico and Massachusetts: place of birth and residence matter. Subst Use Misuse (2010) 45(10):1605-22. doi:10.3109/ 10826081003682842

24. Zhang L, Li J, Lai W, Feng L, Zeng Y, Liu L, et al. Prevalence and correlates of needle-sharing among new and long-term injection drug users in southwest China. Subst Use Misuse (2010) 45(14):2503-23. doi:10.3109/10826084.2010. 487234

25. Neaigus A, Friedman SR, Curtis R, Des Jarlais DC, Furst RT, Jose B, et al. The relevance of drug injectors' social and risk networks for understanding and preventing HIV infection. Soc Sci Med (1994) 38(1):67-78. doi:10.1016/02779536(94)90301-8

26. Hunt N, Lloyd C, Kimber J, Tompkins C. Public injecting and willingness to use a drug consumption room among needle exchange programme attendees in the UK. Int J Drug Policy (2007) 18(1):62-5. doi:10.1016/j.drugpo.2006.11.018

27. Assari S. Over-adjustment Bias by controlling for overall health. Int J Prev Med (2013) 4(4):491-2.

28. Schisterman EF, Cole SR, Platt RW. Overadjustment bias and unnecessary adjustment in epidemiologic studies. Epidemiology (2009) 20:488-95. doi:10.1097/ EDE.0b013e3181a819al

29. VanderWeele TJ. On the relative nature of overadjustment and unnecessary adjustment. Epidemiology (2009) 20(4):496-9. doi:10.1097/EDE. 0b013e3181a82f12

30. Ahmadi K, Rezazade M, Nafarie M, Moazen B, Yarmohmmadi Vasel M, Assari S. Unprotected sex with injecting drug users among Iranian female sex workers: unhide HIV risk study. AIDS Res Treat (2012) 2012:651070. doi:10.1155/2012/651070.

31. Noroozinejad HH, Yarmohmmadi Vasel M, Bazrafkan F, Sehat M, Rezazadeh M, Ahmadi K. Perceived risk modifies the effect of HIV knowledge on sexual risk behaviors. Front Public Health (2013) 1:33. doi:10.3389/fpubh.2013.00033

32. Mirabi P, Yarmohammadi Vasel M, Moazen B, Sehat M, Rezazadeh M, Ahmadi $\mathrm{K}$. Unprotected anal intercourse among Iranian intra-venous drug users. Front Public Health (2013) 1:34. doi:10.3389/fpubh.2013.00034

33. Todd CS, Abed AM, Scott PT, Botros BA, Safi N, Earhart KC, et al. Correlates of receptive and distributive needle sharing among injection drug users in Kabul, Afghanistan. Am J Drug Alcohol Abuse (2008) 34(1):91-100. doi:10.1080/00952990701764771

34. Mokri A. Brief overview of the status of drug abuse in Iran. Arch Iranian Med (2002) 5(3):184-90.

35. Rafiey H, Narenjiha H, Shirinbayan P, Noori R, Javadipour M, Roshanpajouh M, et al. Needle and syringe sharing among Iranian drug injectors. Harm Reduct $J$ (2009) 30(6):21. doi:10.1186/1477-7517-6-21

36. Evans JL, Hahn JA, Page-Shafer K, Lum PJ, Stein ES, Davidson PJ, et al. Gender differences in sexual and injection risk behavior among active young injection drug users in San Francisco (the UFO Study). J Urban Health (2003) 80(1):137-46. doi:10.1093/jurban/jtg137

37. Montgomery SB, Hyde J, De Rosa CJ, Rohrbach LA, Ennett S, Harvey SM, et al. Gender differences in HIV risk behaviors among young injectors and their social network members. Am J Drug Alcohol Abuse (2002) 28(3):453-75. doi:10.1081/ADA-120006736

38. Azim T, Chowdhury EI, Reza M, Ahmed M, Uddin MT, Khan R, et al. Vulnerability to HIV infection among sex worker and non-sex worker female injecting drug users in Dhaka, Bangladesh: evidence from the baseline survey of a cohort study. Harm Reduct J (2006) 3:33. doi:10.1186/1477-7517-3-33

39. Connell RW. Gender and Power: Society, the Person, and Sexual Politics. Stanford, CA: Stanford University Press (1987).

40. Bluthenthal RN, Do DP, Finch B, Martinez A, Edlin BR, Kral AH. Community characteristics associated with HIV risk among injection drug users in the San Francisco Bay Area: a multilevel analysis. J Urban Health (2007) 84(5):653-66. doi:10.1007/s11524-007-9213-3

41. Magis-Rodríguez C, Brouwer KC, Morales S, Gayet C, Lozada R, OrtizMondragón R, et al. HIV prevalence and correlates of receptive needle sharing among injection drug users in the Mexican-U.s. border city of Tijuana. J Psychoactive Drugs (2005) 37(3):333-9. doi:10.1080/02791072.2005.10400528

42. Zamani S, Vazirian M, Nassirimanesh B, Razzaghi EM, Ono-Kihara M, Mortazavi Ravari S, et al. Needle and syringe sharing practices among injecting drug users in Tehran: a comparison of two neighborhoods, one with and one without a needle and syringe program. AIDS Behav (2010) 14(4):885-90. doi:10.1007/s10461-008-9404-2

43. Darke S. Self-report among injecting drug users: a review. Drug Alcohol Depend (1998) 51(3):253-63. doi:10.1016/S0376-8716(98)00028-3

Conflict of Interest Statement: The reviewer Masoumeh Dejman declares that, despite having collaborated with author Shervin Assari, the review process was handled objectively and no conflict of interest exists. The authors declare that the research was conducted in the absence of any commercial or financial relationships that could be construed as a potential conflict of interest.

Received: 04 September 2013; accepted: 16 December 2014; published online: 23 March 2015.

Citation: Assari S, Ahmadi K and Rezazade M (2015) Socio-economic status determines risk of receptive syringe sharing behaviors among Iranian drug injectors; a national study. Front. Psychiatry 5:194. doi: 10.3389/fpsyt.2014.00194

This article was submitted to Addictive Disorders and Behavioral Dyscontrol, a section of the journal Frontiers in Psychiatry.

Copyright $\odot 2015$ Assari, Ahmadi and Rezazade. This is an open-access article distributed under the terms of the Creative Commons Attribution License (CC BY). The use, distribution or reproduction in other forums is permitted, provided the original author(s) or licensor are credited and that the original publication in this journal is cited, in accordance with accepted academic practice. No use, distribution or reproduction is permitted which does not comply with these terms. 